\title{
GETTING 2 ZERO-MIAMI: FILLING THE GAP BETWEEN PROGRAM PRACTICE AND PROGRAM SCIENCE
}

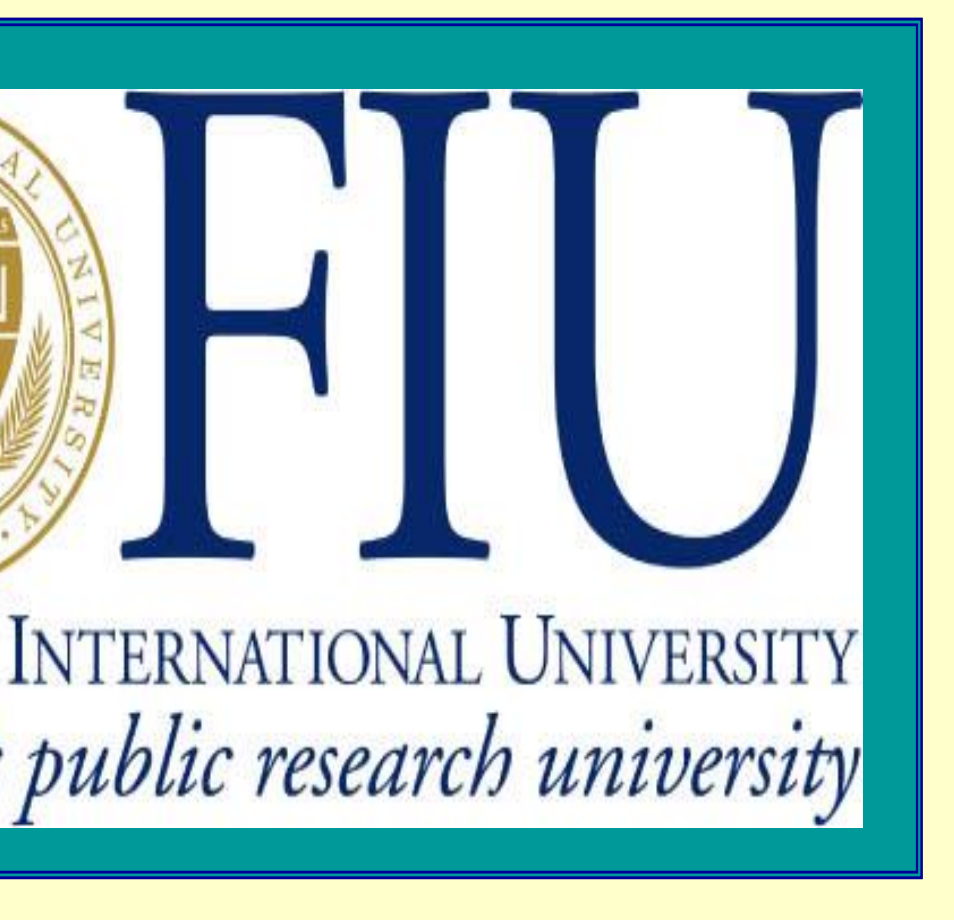

W Darrow, T Brown, Z Blair, M Brown, TY Cooke, E Dormevil, D Felder, J Garcia, M Guzman

Florida International University, Miami, Florida, USA
GRTINGO

YII 0 ,

\section{Background}

Miami-Dade County, Florida, has reported the highest rates of newly diagnosed HIV infections in major municipalities of the United States since national HIV reporting began in 1997. Florida Department of Health (FDOH) representatives, local government officials, and other stakeholders came together as a 29-member Mayor's Task Force on "Getting 2 Zero-Miami" in September 2016 to review and supplement the "2017-2021 Integrated Plan for STD/HIV Prevention and Care." Our research was designed to monitor the implementation of the 16 recommendations made by the Task Force in February and approved by the Mayor's Office in April 2017.

\section{Methods}

Eight Master of Public Health Students enrolled in 2 required courses in health promotion program planning (fall 2017) and evaluation (spring 2018), respectively, agreed to evaluate the implementation process through participant observation at public meetings, e-mail and text messaging, site visits, and conversations with FDOH staff and community members.
Notes were taken, shared, and discussed at weekly meetings of the research team from August 2017 through April 2018. Recommendation-specific reports were compiled, reviewed, and analyzed.

\section{Results}

As of April 30, 2018, 13 recommendations of the Mayor's Task Force were being implemented and three were not (see Table). All four recommendations being implemented solely by FDOH-Miami reported 2-7 actions completed. All four recommendations being implemented jointly by the Ryan White Part A-Minority AIDS Initiative and FDOH-Tallahassee reported 1-4 actions taken. Three recommendations being implemented jointly by the Ryan White Program and FDOH-Miami showed progress, but two did not. The fourth recommendation that lacked progress was a proposal to "provide comprehensive sex education" throughout Miami-Dade public schools.

\section{Conclusions}

Efforts to "expand successful strategies and implement new practices" are moving ahead at an uneven pace. Challenges that remain may best be addressed by the application of program science to local decision-making.

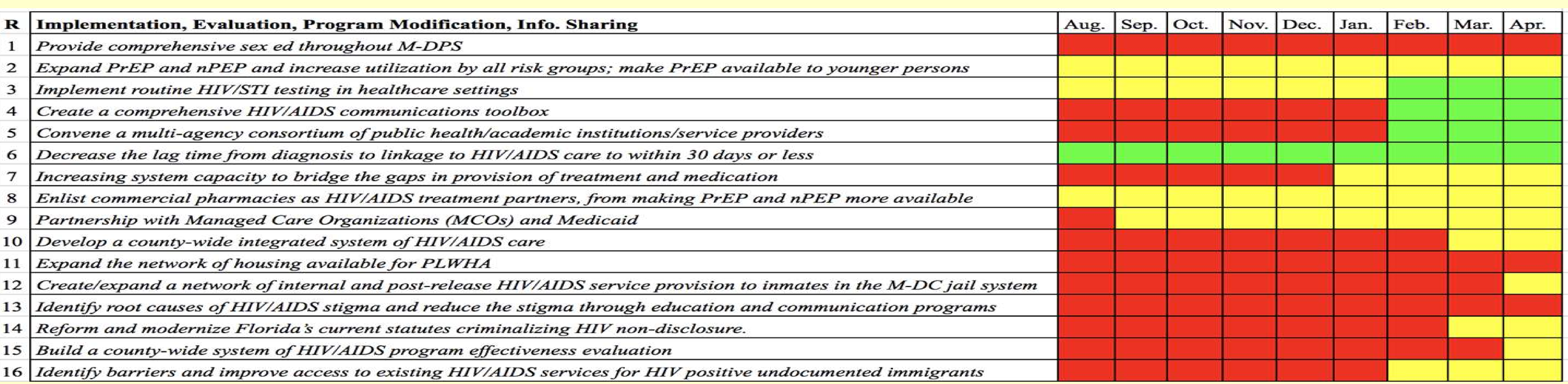

